\title{
pT2N0M0 esophageal squamous cell cancer: Location, grade, and statistics
}

Thomas W. Rice, MD, and Eugene H. Blackstone, MD

Before the 7th edition of the American Joint Committee on Cancer/International Union Against Cancer staging of cancer of the esophagus and esophagogastric junction, all esophageal cancer staging was empirical and relied solely on anatomic cancer characteristics (TNM). ${ }^{1}$ Situ and colleagues ${ }^{2}$ have addressed the most complex interplay of TNM and nonanatomic cancer characteristics included in the 7th edition: pT2NOM0 squamous cell cancer (Figure 1). Stage for stage, survival of patients with esophageal squamous cell cancer is worse than for those with adenocarcinoma, and for early and intermediate stage groupings it is dependent on both cancer location and histologic grade. Despite being unable to discriminate a survival difference among the 3 stage subgroupings to which a pT2NOM0 squamous cell cancer could belong, we find their analysis to be reassuring.

The 7th edition stage groupings were derived with random forest analysis, a machine learning technique that focuses on predictiveness for future patients. ${ }^{3,4}$ Random forest analysis makes no a priori assumptions about survival, is able to identify complex interactions among variables, and accounts for nonlinear effects. Situ and colleagues ${ }^{2}$ have examined goodness of fit or used $P$ values to test for a statistically significant effect of stage on survival, assumed linear effects, and performed limited exploration of interactions. These fundamental differences in statistical methodology reflect the different purposes of the original staging effort and this recent assessment of pT2N0M0 esophageal squamous cell cancer.

Acquisition of data was key to the 7th edition and was a worldwide effort, with 4627 patients undergoing esophagectomy analyzed. ${ }^{5}$ Situ and colleagues ${ }^{2}$ identify 317 patients, 26 in stage IB but most (291) in stage II (96 in stage IIA and 131 in stage IIB). This distribution imbalance is further magnified by the failure to dichotomize

\footnotetext{
From the Department of Surgery, Cleveland Clinic Lerner College of Medicine of Case Western Reserve University, Cleveland, Ohio; and the Department of Thoracic and Cardiovascular Surgery, Heart and Vascular Institute, Cleveland Clinic, Cleveland, Ohio.

Disclosures: Authors have nothing to disclose with regard to commercial support.

Received for publication Jan 25, 2013; accepted for publication Feb 13, 2013; available ahead of print March 18, 2013.

Address for reprints: Thomas W. Rice, MD, Cleveland Clinic Department of Thoracic and Cardiovascular Surgery, 9500 Euclid Ave, Desk J4-1, Cleveland, OH 44195 (E-mail: ricet@ccf.org).

J Thorac Cardiovasc Surg 2013;145:1426-7

0022-5223/\$36.00

Copyright (c) 2013 by The American Association for Thoracic Surgery

http://dx.doi.org/10.1016/j.jtcvs.2013.02.040
}

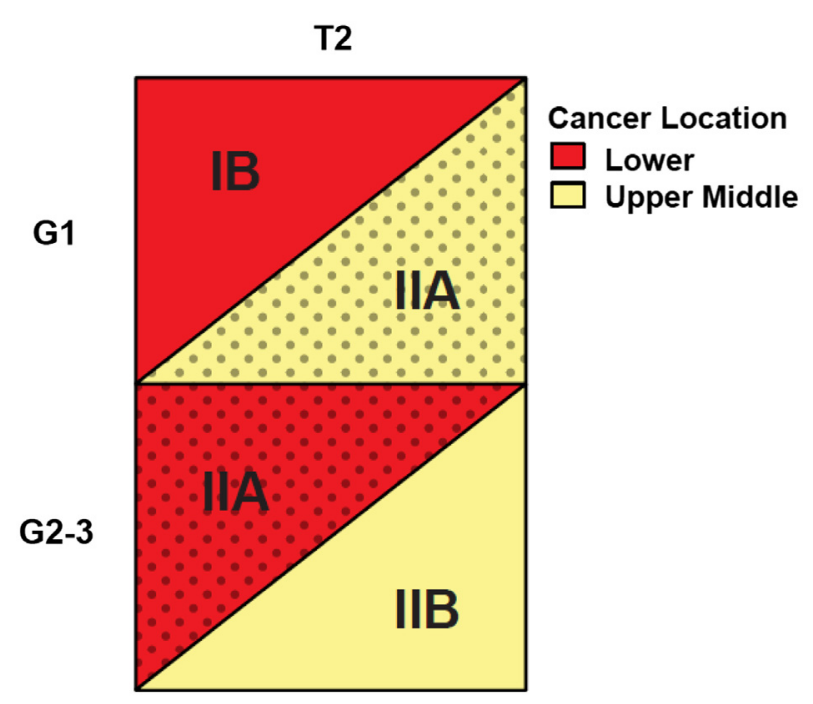

FIGURE 1. Stage groupings for T2NOM0 esophageal squamous cell carcinoma by cancer location and histologic grade $(G)$. G1 is well-differentiated histologic grade, and G2-3 is moderately or poorly differentiated.

nonanatomic cancer characteristics for stage IB, IIA, and IIIB esophageal squamous cell cancer. In the 7th edition, squamous cell esophageal cancer location is either lower esophagus or not, and histopathologic grade is either well differentiated or not. In Situ and colleagues, ${ }^{2}$ cancer location, which was retrospectively acquired, was lower in $58(18 \%)$, and histologic grade was well differentiated in $121(38 \%)$. Even if they dichotomized these variables and only considered the 3 identified combinations of cancer location and histopathologic grade (lower and well differentiated, stage IB; not lower but well differentiated or lower and not well differentiated, stage IIA; and not lower and not well differentiated, stage IIB), there might still be insufficient numbers of patients to detect a survival difference. In their multivariable analysis, however, histologic grade was a significant predictor of survival. Analysis of this small series, when corrected for the dominant effect of grade, revealed an association of cancer location with survival for well-differentiated squamous cell cancers.

Despite the small size of the series, complexities of interactions, and reliance on simple statistics, these findings are reassuring and lead us to conclude, unlike Situ and colleagues, ${ }^{2}$ that for pT2NOM0 squamous cell esophageal cancers, the 7 th edition predicts survival better than 
the 6th edition. We anticipate further improvement with the 8 th edition.

\section{References}

1. Edge SB, Byrd DR, Compton CC, Fritz AG, Greene FL, Trotti A, eds. American Joint Committee on Cancer staging manual. 7th ed. New York: Springer-Verlag; 2010.

2. Situ D, Wang J, Lin P, Long H, Zhang L, Rong T, et al. Do tumor location and grade affect survival of pT2N0M0 esophageal squamous cell carcinoma? J Thorac Cardiovasc Surg. In press 2013.
3. Rice TW, Rusch VW, Ishwaran H, Blackstone EH. Worldwide Esophagea Cancer Collaboration. Cancer of the esophagus and esophagogastric junction: data-driven staging for the 7th edition of the American Joint Committee on Cancer/International Union Against Cancer Staging Manuals. Cancer. 2010; 16:3763-73.

4. Ishwaran H, Blackstone EH, Apperson-Hansen C, Rice TW. A novel approach to cancer staging: application to esophageal cancer. Biostatistics. 2009;10: 603-20.

5. Rice TW, Rusch VW, Apperson-Hansen C, Allen MS, Chen LQ, Hunter JG, et al. Worldwide esophageal cancer collaboration. Dis Esophagus. 2009;221-8. 